Rafael

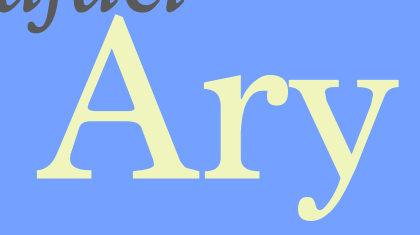

Mario

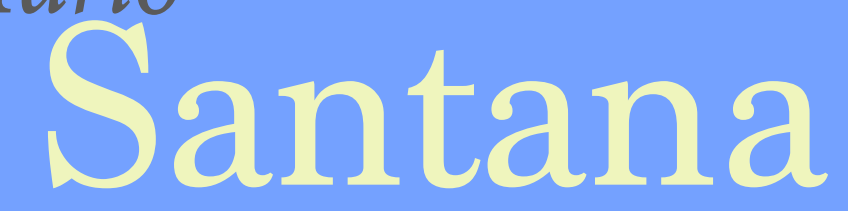

\title{
Da criação coletiva ao processo colaborativo
}

Resumo: $\bigcirc$ intuito deste artigo é discorrer sobre os aspectos que aproximam e distanciam os processos criativos teatrais nomeados de criação coletiva e processo colaborativo, tendo em vista o contexto histórico de cada manifestação.

Palavras-chave: Teatro; Dramaturgia; Processo Criativo. 


\title{
Ra criação coletixa qo processso colaborativo
}

\author{
RAFAEL ARY2 \\ MARIO SANTANA ${ }^{3}$
}

O intuito deste artigo é discorrer sobre os aspectos que aproximam e distanciam os processos criativos teatrais nomeados de criação coletiva e processo colaborativo, tendo em vista o contexto histórico de cada manifestação. Os termos criação coletiva e processo colaborativo são aqui tomados como práticas criativas estabelecidas na história recente das Artes Cênicas e guardam suas origens na busca realizada no ocidente por uma nova maneira de compreender os modos de produção empreendidos após a segunda grande guerra, busca essa que gerou a contracultura e grande parte dos movimentos de protesto dos anos 60 e 70 do século passado.

\section{CRIAC̣ÃO COLETIVA}

A criação coletiva, como movimento relevante, surge para a cena brasileira na década de 1960, entretanto, sua consolidação ocorre ao longo da década de 1970 com o fortalecimento do movimento de teatro de grupo. Já os processos criativos, nomeados como processos colaborativos surgem na década de 1990. O termo se fortalece com a consolidação de coletivos

\footnotetext{
${ }^{2}$ Universidade Federal de Santa Catarina (UFSC). Doutor em Artes da Cena (Unicamp)

${ }^{3}$ Universidade Estadual de Campinas (Unicamp). Doutor em Artes (USP)
} 
de criação com vocação para a pesquisa de linguagem que buscavam alternativas para viabilizar a produção de modo diverso do teatro de encenação, instaurado durante os anos 80 no Brasil.

Uma das referências mais importantes nos estudos de ambos os movimentos na cena brasileira é a pesquisadora Sílvia Fernandes, que em seu livro Grupos Teatrais: Anos 70, apresenta um panorama dos chamados processos de criação coletiva. No trecho a seguir, a autora discorre sobre a ruptura da criação coletiva com o modelo vigente à época.

A preocupação com a experimentação estava pouco presente nos espetáculos, construídos segundo um processo semelhante, que previa a realização eficiente por diretor, atores e técnicos de um texto dramático, escolhido, na maioria das vezes, de acordo com os interesses de um produtor, sem a pretensão de enveredar pelos caminhos mais árduos da pesquisa. Os grupos teatrais vinham modificar esse panorama. Presentes com maior assiduidade a partir de meados da década de 70, dividiam-se em duas correntes claramente identificadas, cuja única semelhança era o projeto coletivo do teatro. Todos os grupos caracterizavam-se como equipes de criação e se organizavam como cooperativas de produção (FERNANDES, 2000, p. 13).

As duas características que a autora destaca como unificadoras das duas correntes dizem respeito à forma como os grupos se organizavam, tanto nas questões mais burocráticas, quanto nas questões relativas à criação. Em ambos, reside, com maior ou menor teor, a ideia de rompimento de uma hierarquia funcional rígida e de não especialização do exercício das diversas funções artísticas específicas. Acima, a autora aponta a raiz comum da perspectiva de produção teatral no movimento de criação coletiva. Mas, para além da necessidade de produzir de modo distinto do modelo comercial 
estabelecido, Sílvia Fernandes divide os grupos que praticavam a criação coletiva em dois tipos: o primeiro, tinha na ideologia política a razão maior para a realização da obra, e desta emergiam todas as diretrizes de trabalho; o segundo, estava centrado na experimentação estética da linguagem cênica e de atuação como exercício de manifestação pessoal dos integrantes dos grupos.

É importante compreender como cada tipo de grupo da criação coletiva procedia. Adiante, Sílvia Fernandes caracteriza:

A primeira tendência, definida pelo teor político das propostas, reunia grupos que desenvolviam atividades na periferia da cidade e se autodenominavam Independentes. Sua principal característica era a intenção de desenvolver uma linguagem popular, conjugada à motivação política. A intenção, nesse caso, era amplamente corroborada pela prática, pois os Independentes afastavam-se do circuito comercial de produção e veiculação do teatro, além de desenvolverem intensa militância com a população mais afastada do centro urbano. Grupos como o Núcleo, o União e Olho Vivo e o Truques, Traquejos e Teatro eram apenas alguns entre os inúmeros que produziam dentro dessa linha de atuação, abandonando o circuito do mercado e optando pelo trabalho árduo nas comunidades periféricas. A sobrevivência era garantida por outras profissões que asseguravam aos artistas a manutenção do ofício teatral, que era antes de tudo um projeto de vida e de participação política na sociedade (FERNANDES, 2000, p. 13).

A tendência descrita acima veio no rastro das iniciativas CPCistas da década de 60, que buscavam a prática de uma arte voltada para o esclarecimento crítico do povo, por isso parecia não querer o rótulo de teatro profissional em suas obras, pelo contrário, os integrantes faziam questão de exercer outras profissões, tendo em vista que o projeto principal desses 
grupos era a conscientização política, principalmente dos trabalhadores e das comunidades mais carentes e marginalizadas. Uma vez que a clara comunicação da temática política era o mais importante, a experimentação estética se dava em função desse objetivo específico. Talvez por isso seja compreensível o estereótipo de obra amadora que marca as referências atuais sobre a criação coletiva.

Distante das certezas políticas, a outra corrente alia-se mais diretamente aos anseios contraculturais que buscavam evitar os modelos estabelecidos no teatro de mercado e instaurar novas possibilidades, conforme afirma ainda Sílvia Fernandes:

$\mathrm{Na}$ segunda corrente, alinhavam-se os grupos mais envolvidos com o teatro como manifestação artística, lúdica, ou, principalmente, como meio eficaz de autoexpressão. Geralmente preocupados com pesquisas de linguagem e trabalhando temáticas próximas ao cotidiano, estavam longe de expressar uma vinculação política. Na maior parte deles, a investigação do teatro e a experimentação de novos modos de fazê-lo aparecia, senão como proposta, ao menos como resultado evidente do processo criativo (FERNANDES, 2000, p. 14).

A experimentação, então, era o eixo desta segunda tendência. Possibilitar experiências como forma de "autoexpressão" gera um teatro com forte caráter improvisacional. Fernandes aponta o grupo carioca Asdrúbal Trouxe o Trombone como exemplar da vertente mais experimental da criação coletiva, que tinha no depoimento pessoal seu alicerce dramatúrgico. $\bigcirc$ grupo também se encaixava nessa tendência por não ter em sua prática nenhuma intenção de se vincular a um pensamento político explícito. Tiveram bastante sucesso em sua trajetória, com espetáculos como 
Trate-me Leão (1977), que tinha o cotidiano da juventude carioca, mais especificamente da zona sul, como tema principal.

Em relação ao exercício de múltiplas funções, característica fundamental da criação coletiva, acreditamos ser necessário compreendê-la na condição em que acontece - uma expressão da identidade de um coletivo que se afirma em contraposição à realidade de mercado estabelecida, da configuração dos elementos componentes da obra participavam todos os integrantes, como afirmado a seguir.

A célula grupal, em geral, bastava-se em todos os aspectos e a assunção dessa possibilidade opera uma redefinição da teatralidade. Do interior do grupo saía, então, tudo o que fosse preciso para o espetáculo: cenário, música, texto, iluminação, figurino, interpretação, tudo era expressão de sua identidade própria (SANTANA, 1997, p. 69).

O caráter de polivalência artística, exposto na citação acima, parece ser um ponto ideal a ser alcançado, mas que nem sempre se efetiva na prática de criação. Claro que isso ocorria em função do fato de que a maioria dos grupos não tinha um especialista para certas funções, como iluminador, cenógrafo, figurinista etc. Em outros casos, alguns não estabeleciam as funções em virtude de um projeto estético já delineado, que era abdicar da realização de um resultado com 'cara profissional', posto que esse reproduziria o padrão imposto pelo teatro comercial e, outros, não tinham condições sequer de contar com um especialista na área. Então, todos buscavam participar da feitura de tudo ou do que melhor "dominava".

A esses grupos parece menos importante a transmissão de uma ideia ou mensagem redutível à verbalização, do que a 
organização poética da representação de modo a instaurar uma cumplicidade entre os participantes. Importa mais que o espetáculo proporcione a atores e espectadores uma vivência integral de suas necessidades de libertação, e não que cumpra apenas seu papel tradicional de entretenimento ou de esclarecimento crítico. (...) Do Rio Grande do Sul ao Amazonas experimenta-se a cena como espaço de discussão do real, mas, consciente ou inconscientemente experimentase fazer teatro como exercício de libertação, para exorcizar a insegurança que paira (SANTANA, 1997, p. 70-71).

A criação coletiva pretendia artistas polivalentes que exercessem todos os aspectos funcionais da cena e, nisto, estava implícito uma proposta de libertação do artista das funções especializadas, reflexo de um movimento de contracultura, que via nas especializações uma situação análoga aos trabalhadores das linhas de produção de fábricas do começo do século 20.

Muitas são as razões levantadas para o surgimento da criação coletiva. Tanto os elementos conjunturais da época marcada pela contracultura, pelo movimento hippie e seu projeto comunitário, pelo ativismo político e libertário acentuado - quanto as necessidades especificamente teatrais - falta de uma dramaturgia que se moldasse perfeitamente às inquietudes sociais, temáticas e estéticas dos grupos de teatro de então, ou ainda, a busca de uma relação mais participativa com o público - tudo isso é invocado para justificar o aparecimento deste novo modo de criação (ARAÚJO, 2008, p. 28).

Pode-se dizer que a criação coletiva é um modo de fazer e pensar teatro que nasce de um momento político peculiar na história do Brasil, logo, as questões contextuais se colocam à frente das questões estéticas da cena, 
ou mesmo da metodologia de trabalho, mesmo quando os grupos não se filiam a um ideal político reconhecível.

A Tribo de Atuadores Ói Nóis Aqui Traveiz, do estado do Rio Grande do Sul, que surgiu em 1978 e, até hoje, se mantém em atividade, é outro grupo que podemos chamar de modelar para entender a criação coletiva no Brasil. Seu tempo de atividade é tão extenso, que foi capaz de passar por diversos modos de fazer da criação coletiva.

Poucas são as companhias teatrais que ainda definem sua prática como criação coletiva, por uma série de razões, entre elas por caracterizar um movimento muito particular das décadas de 60 e 70. Notamos algumas resistências das companhias teatrais da atualidade, quando se trata da terminologia criação coletiva. (...) muitas vezes o termo compreende uma série de associações pejorativas, como amadorismo, anarquia, experimentalismo, enfim, é definida como uma cultura teatral menor. Como uma das exceções no panorama de teatro de grupo brasileiro, a Tribo de Atuadores Ói Nóis Aqui Traveiz faz questão de manter tal denominação para a sua prática (FISCHER, 2003, p. 53).

Nessa trajetória de criações coletivas, o tema escolhido como motivo para a criação de uma obra era a argamassa que unia o conjunto de participantes, configurava as margens que guiavam as individualidades por um mesmo caminho, afunilando questões para um centro criativo anárquico, mas orientado em seu ponto mais distante pela temática em investimento, tão importante como uma bússola para marinheiros perdidos em alto-mar.

A dramaturgia surge mais de recortes de fragmentos redimensionados na cena do que de uma escrita própria - a autoria, neste campo, se concentra na roteirização e na concepção das cenas. Na maioria das vezes, parte-se de um 
texto dramático do qual se extrai um tema que será estudado e resultará em ramificações cênicas sem texto ou com palavras colhidas de outras fontes (TROTTA, 2008, p. 257).

É interessante perceber que muitos espetáculos foram criados pela Tribo de Atuadores Ói Nóis Aqui Traveiz a partir de um texto literário ou teatral. Logo, a presença do dramaturgo se dá pela obra escolhida e a função dramaturgia se realiza sem a interferência direta do autor. As obras acabam por fornecer questões temáticas, sendo assim recriadas totalmente ou utilizadas em sua totalidade, aproveitando-se suas estruturas e diálogos.

Na sua longa trajetória figuram encenações como (as mais recentes): Fim de Partida, de Samuel Beckett (1986); Ostal, de Aldo Rostagno (1987); Antígona, Ritos de Paixão e Morte (1990); Missa para Atores e Público sobre a Paixão e o nascimento do Doutor Fausto, de Acordo com o Espírito de Nosso tempo (1994); Álbum de Família, de Nelson Rodrigues (1996); A Morte e a Donzela, de Ariel Dorfam (1997); A Exceção e a Regra, de Bertolt Brecht (1998); Hamlet Máquina, de Heiner Muller (1999), A Saga de Canudos (2000); Aos Que Virão Depois de Nós - Kassandra in Process, baseado na novela de Christa Wolf (2002) (FISCHER, 2003, p. 47).

Nesse contexto, o coletivo acaba por tomar, de certa maneira, para si a função dramaturgia. Na tentativa de um norte, mesmo que sutil - que não exija a presença de um dramaturgo -, recorre-se à utilização de obras literárias ou dramáticas, a partir das quais se possa praticar um olhar particular no processo de exploração das mesmas, as quais podem vir a se distanciar completamente da fonte original.

A criação coletiva preconizava a não existência das delimitações oficiosas na feitura da obra teatral, visando assim a fuga de um teatro 
funcionalista, preocupado com o produto acima de qualquer coisa. Qualquer proposição sustentada na ideia de pretensa eficácia metodológica, com motivações voltadas apenas para um resultado mais deglutível pelo mercado - como a adoção de profissionais especializados nas diversas áreas de atuação -, era visto como usurpação do processo. "Tais aspectos, a abolição da função especializada e a polivalência artística - elementos estreitamente vinculados um ao outro - constituem um eixo fundamental para nossa reflexão sobre a criação coletiva." (ARAÚJO, 2008, p. 27)

Naquilo que foi relatado como criação coletiva, existem algumas contradições entre o que é teoricamente defendido e o que a prática demonstrou. Olhando em retrospectiva, percebemos que em alguns grupos representantes da criação coletiva, com o passar do tempo, surgiram lideranças que conduziram a trajetória artística dos grupos ao qual pertenciam, colocando em xeque a pretensa inexistência de hierarquia entre os envolvidos. Temos como caso exemplar o grupo estadunidense Living Theatre, que possuía como lideranças históricas Julian Beck e Judith Malina. Como aponta o estudo que Pierre Biner realizou sobre o grupo a partir de depoimentos de seus integrantes:

A comunidade do Living é, de certa maneira, penso eu, o aspecto mais importante do nosso trabalho. É talvez, também, por agora, o aspecto menos perfeito. É mais um conceito do que uma coisa real. Nós queríamos que esta comunidade funcionasse verdadeiramente como uma associação anarquista. Quando falamos de liberdade, queremos dizer que é preciso criar uma sociedade em que a coletividade não seja sacrificada ao indivíduo e em que o indivíduo não o seja à coletividade. (...) Judith e eu nos esforçamos por desaparecer, por nos fundirmos na coletividade. Apagamo-nos pouco a pouco, como queríamos que o Estado o fizesse. (...) Queríamos chegar ao ponto em 
que o trabalho teatral fosse realmente uma obra coletiva. Judith e Julian continuam a ocupar um lugar central. Não se pode, portanto, dizer que tenhamos atingido o nosso objetivo (BINER, 1973 citado por TROTTA, 2008, p. 44).

Mesmo com um cabedal teórico renitente, a liderança se sobrepõe ao ideal anarquista de coletividade. O Living se caracteriza, com o passar do tempo, por uma grande rotatividade interna de participantes. Se somarmos a isso a manutenção dos mesmos diretores, obtemos o fortalecimento de lideranças, frente a novos aprendizes de um modelo que está sempre por vir a ser, por se concretizar.

Notamos que mesmo em grupos que se estruturam em bases coletivas, a presença de um líder ou diretor faz-se necessária. Assim como Julian Beck estava para o Living Theatre ou José Celso Martinez Corrêa para o Oficina, Hamilton Vaz Pereira era o mediador do Asdrúbal Trouxe o Trombone, Naum Alves de Souza era o eixo centralizador no início do Pod Minoga e Carlos Alberto Soffredini coordenava as pesquisas cênicocircenses do Mambembe. Esses exemplos atestam a importância do diretor na criação em grupo (FISCHER, 2003, p. 16).

Há então certo paradoxo: como grupos que pregam a polivalência artística, uma total anarquia criativa, onde não há nenhuma função explícita nem dominante, tem na figura do diretor um papel tão representativo? A liderança não é assumida em muitos casos. $\bigcirc$ discurso proferido continua o da liberdade e paridade das relações, o que pode escamotear um controle ainda maior do fluxo criativo. A forma mais perversa de controle em um processo criativo, a nosso ver, acontece quando se invoca a entidade "processo" para intermediar a criação. Logo, não é mais o desejo de um 
sujeito que se estabelece e, sim, o do processo, que é superior a todos os sujeitos, incensurável, e que sabe o melhor rumo para o espetáculo. Alguns integrantes se tornam representantes oficiais dessa entidade durante a criação. Araújo analisa essa possível forma de controle que é fomentada em um ambiente onde teoricamente existe total liberdade de criação:

Muitas vezes, também, essa perspectiva do "todo mundo faz tudo" escondia certos traços de manipulação. Por exemplo, determinado dramaturgo ou diretor pregava tal discurso coletivizante visando camuflar um desejo de autoridade e, dessa forma, evitava confrontos e conflitos com os outros integrantes do grupo. Negar o poder pode ser uma forma de reafirmá-lo ou de exercê-lo, ainda que sub-repticiamente. Ditaduras ou tiranias podem também se instaurar de maneira difusa, escamoteadas atrás de um discurso de participação e liberdade (ARAÚJO, 2002, p. 123).

$\mathrm{Na}$ criação coletiva, a dramaturgia realizada por dramaturgos reconhecidos, mas ausentes do processo de criação e que exigiam a reprodução fiel de seus escritos em cena, foi identificada como uma das funções que representavam essa individualidade de modo mais explícito, por isso, muitas vezes os grupos optavam por não ter como diretriz do processo de criação um texto dramatúrgico pronto. A ausência do dramaturgo do processo de trabalho foi, quem sabe, uma maneira de repensar a função em si. Assim, em seu retorno, mais adiante no tempo, já no processo colaborativo, a função dramaturgia é reposta em um patamar equânime em relação às outras funções.

Se considerarmos a presença de funções artísticas específicas, o ambiente propício à contribuição recíproca entre essas funções, o tema como eixo da criação e o grupo como representante do discurso teatral - 
sendo estas características presentes em alguns grupos da criação coletiva , nos parece, por vezes, que a grande diferença da criação coletiva para o processo colaborativo reside, de fato, na ausência do dramaturgo na sala de ensaio.

Para fazer o paralelo entre a criação coletiva e o processo colaborativo, as chaves de leitura podem ser: a questão da especialização das funções e as relações hierárquicas. $O$ processo colaborativo possui funções especializadas, apesar da permeabilidade artística amplamente estimulada, e a hierarquia entre estas funciona de modo flutuante, ou seja, cada etapa do processo exige que uma função esteja no foco da criação.

A princípio, parece necessário compreender que o processo colaborativo não possui nenhuma vertente ou se vincula a uma práxis política direta, antes a uma práxis poética com caráter político em virtude de configurar-se como uma "saída" para a independência em relação à figura do encenador dominante na época em que surge. Assim, não nasce como manifesto, mas como um retorno às experiências coletivas de criação em grupo e, dessa maneira, se aproxima mais da vertente experimental da criação coletiva. Todavia, hoje é perceptível que há grupos identificados com o processo colaborativo que mesclam a experimentação estética com um posicionamento político, no que concerne aos temas relevantes, como violência urbana, religião, entre outros. 
No Teatro da Vertigem, por exemplo, a forma de abordar o tema a ser trabalhado exige um posicionamento político, pois estes pedem e mobilizam opiniões, tanto dos artistas que empreendem a cena, quanto do público que compartilha dessas experiências. Assim, o "que" dizer é tão importante quanto o "como" dizer. Nesse sentido, o processo colaborativo quebra uma relação de hierarquia entre a forma e o conteúdo, entre prevalência do discurso ou prevalência da experimentação estética radical. Por fim, evita a cena produzida a partir da visão pessoal, radicalizada na figura do encenador, priorizando a cena produzida a partir das visões pessoais do coletivo em criação, ainda que com a presença de um diretor.

Podemos perceber que inicialmente a ligação entre a criação coletiva e o processo colaborativo reside no fortalecimento do movimento de teatro de grupo. Nas duas experiências é possível perceber a ideia de coletivo como uma forma de apoio mútuo entre os participantes, uma maneira de se organizar em busca de oportunidades e fortalecimento de posições. Fischer, em sua dissertação de mestrado, destaca o contexto histórico para o surgimento da expressão processo colaborativo. Segundo a pesquisadora, a retomada das criações em grupo são motivadas por forças econômicas, estruturais e artísticas.

Acreditamos que o clima de instabilidade econômica e as contradições das leis de incentivo fiscal propiciaram a retomada das cooperativas teatrais. A distribuição da renda de forma equitativa resulta na formação de associações, corporações autônomas e empresas culturais de propriedade e valores coletivos. Essa tendência, frequente na década de 70, volta não de forma nostálgica, mas revigorada e com expressiva interferência no contexto sociocultural brasileiro. O teatro de grupo torna-se um fenômeno da cena dos anos 90, difundindo-se por toda extensão do território nacional, 
como alternativa não apenas de resistir às dificuldades econômicas, mas como perspectiva de artistas, coletivamente, empreender suas atividades e pesquisas (FISCHER, 2003, p. 27).

P processo colaborativo, a nosso ver, não representa uma ruptura, mas uma tentativa de agregar elementos da criação coletiva e da chamada década do encenador (1980) para o aprimoramento da experiência da criação teatral. Assim como a criação coletiva foi uma resposta ao modo de criar teatro de sua época, o processo colaborativo parece exercer o mesmo papel.

Stela Fischer afirma que o processo colaborativo provém, em linhagem direta, da chamada criação coletiva da década de 1970, como observamos no trecho a seguir:

A partir dessa definição da cena contemporânea, podemos definir o processo colaborativo como um prolongamento da criação coletiva setentista. $O$ que se faz urgente é a necessidade de inaugurar uma nova terminologia que defina a prática em grupo que não esteja associada ao termo criação coletiva. Isso devido a uma série de preconceitos e estigmas que imbuíram a criação coletiva com significados equivalentes ao amadorismo e experimentalismo, muitas vezes dissociados da fundamentação teórica e prática (FISCHER, 2003, p. 42).

O dramaturgo e diretor Reinaldo Maia escreveu um texto, Duas ou Três Coisinhas sobre o Processo Colaborativo, no qual o autor questiona se as raízes do processo colaborativo estão realmente ligadas à criação coletiva. 
E aqui está uma diferença fundamental com o "Processo Colaborativo", onde a cena é que sobredetermina. (...) no "Processo Colaborativo" o "fazer", a Prática é que sobredetermina o "pensar", a Teoria. Pode parecer pouco, mas é fundamental para se entender uma das vertentes da encruzilhada em que se encontra o processo criativo atualmente. ${ }^{4}$

Para Reinaldo Maia, a criação coletiva tinha suas raízes fincadas no marxismo, no teatro político de Brecht, somente para ficar com as principais influências, enquanto o processo colaborativo, para ele, era expressão de uma realidade capitalista, neoliberal, em consonância com o momento social e político do Brasil da década de 1990. A criação coletiva agregava, muitas vezes, questões ideológicas que refletiam em seu modo de proceder, referentes ao momento político da década de 1970.

O "Processo de Criação Coletiva" de alguma maneira, em estrito senso político, é a solução encontrada para uma criação estética que encontra-se sufocada pela censura, pelos cerceamentos políticos organizacionais, que busca formas de driblar, de continuar exercendo sua função social e contribuir para a "formação de quadros", que possam ajudar na luta pela redemocratização do país. A "Criação Coletiva" dos anos 60/70 não é, assim, uma resposta apenas para a solução dos problemas da cena, mas para a formação de um "Pensar" que se contrapusesse ao pensamento autoritário vigente. Ou seja, a possibilidade do "criador" poder circular e discutir as instâncias do "espetáculo" era uma maneira didática de formar um "pensamento" que tivesse em consideração o Todo e soubesse avaliar as Partes. Digo didático porque a esperança daqueles que praticaram e vivenciaram essa prática era de que esse conhecimento pudesse,

\footnotetext{
${ }^{4}$ Reinaldo Maia. Duas ou três coisinhas sobre o processo colaborativo. Texto não publicado. 2004 , p. 3.
} 
analogicamente, ser transferido para a compreensão e análise da Sociedade e Política como tal. ${ }^{5}$

Sendo assim, o parentesco entre a criação coletiva e o processo colaborativo está longe de ser consenso. A pesquisadora Rosyane Trotta também salienta o aspecto ideológico como diferença inconciliável entre os dois modos:

Se, aos olhos de um apressado pesquisador, o processo colaborativo parece uma evolução da criação coletiva, a análise recorre implicitamente a parâmetros como especialização e eficiência, extraídos do modelo capitalista, que não condizem com a prática de uma modalidade teatral que deseja justamente se apartar daquele modelo (TROTTA, 2008, p. 265).

A trilha de argumentação de Rosyane Trotta e Reinaldo Maia, na qual a ideia de especialização parece estar intimamente ligada a uma noção de modo de produção capitalista, nos leva à conclusão de que o processo colaborativo tem seu surgimento intimamente relacionado ao momento político dos anos 1990 e possui uma preocupação exacerbada com a operacionalização do fazer cênico. A partir das ideias dos autores acima, a especialização das funções é traduzida como procedimento para alcançar resultados eficientes. A vinculação ou total desvinculação da criação coletiva ao processo colaborativo se torna uma questão de posicionamento ou modo de argumentação. Porém, para além das polêmicas que se referem à vinculação entre os dois modos de trabalho, acreditamos que o tema, como

\footnotetext{
${ }^{5}$ Reinaldo Maia. Duas ou três coisinhas sobre o processo colaborativo. Texto não publicado. 2004, p. 2.
} 
guia da criação, é um aspecto em comum de grande relevância na análise empreendida, pois está presente de modo substancial em ambas as experiências coletivas de criação.

O dramaturgo Luís Alberto de Abreu, que afirma que o processo colaborativo tem raízes na criação coletiva, é um exemplo de artista que pôde viver tanto a criação coletiva, como espectador, quanto o processo colaborativo, como artista. É interessante perceber que a formação artística de Abreu contém um cabedal ideológico compartilhado com muitos praticantes da criação coletiva.

Minha formação foi na década de 70, então as ideias marxistas me influenciaram muito. A História talvez seja minha primeira influência, depois da literatura. Quem marcou a minha formação em literatura foi Dostoiévski, esse foi um sujeito que me marcou muito. Na minha juventude os primeiros foram Dostoiévski e Górki. Os russos, de uma forma geral. (...) Em teatro, lá na década de 70, a minha influência maior era o Brecht. ${ }^{6}$

Reinaldo Maia, ao generalizar a criação coletiva como meio de propagação de uma ideologia específica, elimina qualquer possibilidade de ligação entre a mesma e o processo colaborativo. Como vimos, a criação coletiva possuía muitas facetas. Grupos, como o Asdrúbal Trouxe o Trombone, não partilhavam de um pensamento marxista, brechtiano, mas eram praticantes da criação coletiva, assim como a Companhia do Latão, que possui ideologia marcadamente socialista, se alinha aos valores do processo colaborativo. A Companhia do Latão (SP), como afirmado, é um exemplo de

\footnotetext{
${ }^{6}$ Luís Alberto de Abreu em entrevista concedida em 13.10.2009.
} 
grupo que trabalha com funções bem definidas, ao modo do processo colaborativo. Sérgio de Carvalho, diretor e dramaturgo do grupo, põe em xeque a diferenciação entre os dois termos:

Todas as peças que escrevi até hoje foram baseadas no que se costuma chamar de processo colaborativo. A rigor é o mesmo procedimento que no passado foi chamado de criação coletiva, sendo que diferenças conceituais só podem ser estabelecidas caso a caso. São tantas as formas de criação coletiva quanto os grupos que as praticam. O que há de comum, se eu não estiver enganado, é o fato de que o material dramatúrgico, as personagens e o conjunto das relações ficcionais e estéticas surgem na sala de ensaio, com base nas improvisações dos atores e nos debates do grupo sobre um tema ou projeto formal (CARVALHO, 2009, p. 67).

É importante ressaltar que a Companhia do Latão tem declaradamente um viés ideológico, que se alinha ao de Reinaldo Maia, por isso, talvez, sua tendência em nomear sua prática como criação coletiva. Por outro lado, Antônio Araújo, ao falar sobre a relação entre processo colaborativo e criação coletiva, delimita com veemência os campos:

Eu não acho que seja a mesma coisa. Às vezes me parece que quem quer dizer que é a mesma coisa está muito ligado, algumas vezes, a uma ideia de que continuar chamando de criação coletiva, como a criação coletiva tem essa matriz no comunismo, no agitprop, é quase uma opção ideológica, ou política. Para mim não é a mesma coisa. ${ }^{7}$

\footnotetext{
${ }^{7}$ Antônio Araújo em entrevista concedida em 21.09.2009.
} 
O esforço de teorização que foi realizado por alguns autores a respeito da criação coletiva possui discrepâncias relevantes quando relacionada com a prática observada. A teorização, vista de hoje, apontava soluções ideais para questões complexas, como a hierarquia entre os criadores, a abolição de especialidades artísticas funcionais, sem fazer uma crítica mais aprofundada. Esta reflexão torna-se importante para que a análise empreendida neste artigo não perca o caráter crítico necessário para o entendimento dos fenômenos estudados. Quanto mais distante a teoria está da prática, mais esta se parecerá com uma paisagem morta.

O processo colaborativo pode ser visto como a fusão das duas tendências apontadas por Sílvia Fernandes, hierarquia e exercício das funções artísticas, pois tende a criar a partir de temáticas com caráter político citadino, mas as empreende por meio de procedimentos criativos que levam em consideração a participação de todos os envolvidos nas diversas funções, embora as mesmas tenham responsáveis específicos, muitas vezes especialistas em seus campos. É possível afirmar que os praticantes da criação coletiva, do processo colaborativo ou mesmo do chamado, muitas vezes pejorativamente, "teatrão" tenham seus objetivos a alcançar em cada trabalho empreendido, entretanto, nada garante o êxito. Mais relevante do que analisar resultados estéticos e seu alcance, é perceber a intenção do artista por detrás da obra. O impulso criador deveria ter destino certo: o público. Seja comungar temáticas políticas, seja proporcionar uma experiência sensorial, a intenção por detrás do artista deve ser apreensível quando há a fricção entre a obra e o público. 


\section{REFERÊNCIAS BIBLIOGRÁFICAS}

ARAÚJO, Antônio. A gênese da Vertigem: o processo de criação de $O$ Paraíso Perdido. 2002. Dissertação - Universidade de São Paulo, Escola de Comunicações e Artes, São Paulo, SP.

A encenação no coletivo: desterritorializações da função do diretor no processo colaborativo. 2008. Tese - Universidade de São Paulo, Escola de Comunicações e Artes, São Paulo, SP.

ARY, Rafael. A função dramaturgia no processo colaborativo. 2011. Dissertação - Universidade Estadual de Campinas, Instituto de Artes, Campinas, SP.

CARVALHO, Sérgio de. Introdução ao teatro dialético: experimentos da Companhia do Latão. São Paulo, SP: Expressão Popular, 2009.

FERNANDES, Sílvia. Grupos teatrais: anos 70. Campinas, SP: Editora da Unicamp, 2000.

FISCHER, Stela. Processo colaborativo: experiências de companhias teatrais brasileiras dos anos 90. 2003. Dissertação - Universidade Estadual de Campinas, Instituto de Artes, Campinas, SP.

SANTANA, Mario A. de. A desconstrução do texto para a construção da cena: reflexões sobre a fala da cena no teatro brasileiro recente. 1997. Dissertação - Universidade Federal do Rio de Janeiro, Faculdade de Letras, Rio de Janeiro, RJ.

TROTTA, Rosyane. A autoria coletiva no processo de criação teatral. 2008. Tese - Universidade Federal do Estado do Rio de Janeiro, Centro de Letras e Artes, Rio de Janeiro, RJ. 
ABSTRACT: The purpose of this article is to discuss about the main characteristics of theatrical creative process named collective creation and collaborative process, considering the historical context of each approach.

KEYWORDS: Theatre; Playwriting; Creative Process. 